\title{
Effect of reduced risk pesticides on greenhouse vegetable arthropod biological control agents
}

\author{
Angela E. Gradish, ${ }^{a}$ Cynthia D. Scott-Dupree, ${ }^{a *}$ Les Shipp, ${ }^{b}$ C. Ron Harris ${ }^{a}$ \\ and Gillian Fergusonc
}

\begin{abstract}
BACKGROUND: Arthropod biological control agents (BCAs) are commonly released for greenhouse vegetable insect pest management. Nevertheless, chemicals remain a necessary control tactic for certain insect pests and diseases and they can have negative impacts on BCAs. The compatibility of some formulated reduced risk insecticides (abamectin, metaflumizone and chlorantraniliprole) and fungicides (myclobutanil, potassium bicarbonate and cyprodinil + fludioxonil) used, or with promise for use, in Canadian greenhouses with Orius insidiosus (Say), Amblyseius swirskii (Athias-Henriot) and Eretmocerus eremicus (Rose \& Zolnerovich) was determined through laboratory and greenhouse bioassays.
\end{abstract}

RESULTS: Overall, the insecticides and fungicides were harmless as residues to adult BCAs. However, abamectin was slightly to moderately harmful to $O$. insidiosus and $A$. swirskii in laboratory bioassays, whereas metaflumizone was slightly harmful to $E$. eremicus.

CONCLUSIONS: In general, these products appear safe to use prior to establishment/release of these adult BCAs.

(C) 2010 Society of Chemical Industry

Keywords: pesticide; toxicity; Orius insidiosus; Amblyseius swirskii; Eretmocerus eremicus; greenhouse

\section{INTRODUCTION}

Greenhouse vegetables are sold exclusively for fresh market consumption and demand for a blemish-free product from consumers makes effective pest management crucial. Integrated pest management (IPM) is commonly practiced and growers rely heavily on biological control as part of IPM for insect pests. Biological control has some advantages compared to chemical control: it is relatively easy to initiate, can be more effective, and reduces chemical use, minimizing worker exposure, residues and environmental pollution..$^{1,2}$ Currently, western flower thrips (Frankliniella occidentalis Pergande) (WFT) and greenhouse whitefly [Trialeurodes vaporariorum (Westwood)] (GWF), two common and potentially devastating greenhouse vegetable insect pests, are primarily managed using commercially available arthropod biological control agents (BCAs). However, because effective BCAs are not available for control of all pests, pesticides remain an important management tactic in greenhouse IPM. Some insect pests occasionally require insecticide application and fungicides remain the primary control tactic for powdery mildew (PM) [tomato: Oidium neolycopersici (Kiss); cucumber: Podosphaera xanthii (Castagne); pepper: Leveillula taurica (Lev.)]. ${ }^{3}$ Some of these pests have developed resistance to currently registered products, and development of chemicals with novel modes of action for use in greenhouse vegetable production is needed.

Despite their usefulness in greenhouse pest management, pesticides can have negative non-target effects, specifically on BCAs. Knowledge of pesticide toxicity to BCAs is necessary for successful implementation of biological and chemical control methods in IPM programs. Biological control agents are at risk of pesticide exposure in greenhouses by direct contact with spray during foliar application or by contacting residues on plants, which can result in mortality and/or sub-lethal effects. ${ }^{4}$ As BCAs are purchased from commercial companies, their mortality can result in substantial economic loss for the grower. The elimination of BCA populations also can cause pest population resurgence, or a secondary pest outbreak resulting from loss of control of the target pest. ${ }^{5}$ Insecticides can be particularly detrimental to BCAs. ${ }^{6}$ Fewer data are available on the effect of fungicides, but some studies suggest they have the potential to harm beneficial arthropods. ${ }^{7,8}$ Development of reduced risk pesticides, which are more toxic to their intended target pest than to beneficial species, has improved the incorporation of BCAs into IPM programs; however, even these products can be harmful. ${ }^{4}$ Therefore, it is important to evaluate reduced risk pesticides for use in greenhouse vegetable IPM for their potential non-target effects on BCAs.

The objective of this study was to determine the potential toxicity of several reduced risk insecticides and fungicides used or with

\footnotetext{
Correspondence to: Cynthia D. Scott-Dupree, School ofEnvironmental Sciences, University of Guelph, Guelph, Ontario, Canada, N1G 2W1.

E-mail:cscottdu@uoguelph.ca

a School of Environmental Sciences, University of Guelph, Guelph, ON, Canada, N1G 2W1

b Agriculture and Agri-Food Canada, Greenhouse and Processing Crops Research Centre, Harrow, ON, Canada, NOR 1 GO

c Ontario Ministry of Agriculture, Food and Rural Affairs, Harrow, ON, Canada, NOR $1 G 0$
} 
promise for use in Canadian greenhouse vegetable production to three species of commonly released BCAs [Orius insidiosus (Say), Amblyseius swirskii (Athias-Henriot), and Eretmocerus eremicus Rose and Zolnerowich] for GWF and WFT control.

\section{MATERIALS AND METHODS}

\subsection{Arthropod rearing}

Orius insidiosus adults were obtained from a colony at the University of Guelph established from insects purchased from Biobest Biological Systems Canada Ltd., Leamington, ON (BBSC) and Koppert Biological Systems Canada Ltd., (Leamington, ON (KBSC). Adults and nymphs were reared separately in ventilated plastic containers $\left(739 \mathrm{~mL}\right.$ disposable Glad $^{\circledR}$ Servin Savers) containing green bean (Provider, Vesey's Seeds Ltd., York, PEI) leaves and pods for moisture and oviposition sites, respectively. Adults and nymphs were provided with Ephestia kuehniella Keller eggs (Beneficial Insectary, Oakrun, CA) sprinkled on moistened card stock strips for food. The colony was maintained at $25 \pm 1{ }^{\circ} \mathrm{C}, 75-80 \% \mathrm{RH}$ and 16:8 h light: dark photoperiod.

Amblyseius swirskii adults were purchased from BBSC and cohorts reared to obtain adults of a known age. On arrival, $A$. swirskii adults were transferred in groups of ca. 50 to rearing arenas which consisted of a sponge cut to fit into a plastic dish (11 cm diameter $\times 4 \mathrm{~cm}$ height). Water was added until the sponge was saturated and the water line was just below the top edge of the sponge. A green bean leaf cut in a square was laid on top of the sponge with the abaxial surface upwards. Cattail (Typha latifola L.) pollen was sprinkled on the leaf for food and a small amount of cotton wool was provided as an oviposition site. Eggs were collected daily using a fine-hair paint brush and were transferred to fresh arenas. Cohorts were used for bioassays ca. $24 \mathrm{~h}$ after adult emergence and were maintained at $25 \pm 1{ }^{\circ} \mathrm{C}, 70 \% \mathrm{RH}$ and $12: 12 \mathrm{~h}$ light: dark photoperiod.

Eretmocerus eremicus larvae were purchased from BBSC as parasitized whitefly pupae on hanging cards. Pupae were cut from cards and placed in plastic vials $(2 \mathrm{~cm}$ diameter $\times 7 \mathrm{~cm}$ height) with ventilated snap lids. A small drop of honey (ca. $2 \mathrm{~mm}$ diameter) was placed on the inside of each lid for food. Vials were kept at $25 \pm 1{ }^{\circ} \mathrm{C}, 70 \% \mathrm{RH}$ and $12: 12 \mathrm{~h}$ light: dark photoperiod, and adults were used for bioassays ca. $24 \mathrm{~h}$ after emergence.

\subsection{Pesticide treatments}

Formulated insecticides, abamectin $190 \mathrm{~g} \mathrm{~L}^{-1}$ EC (Avid ${ }^{\circledR}$, Syngenta Crop Protection Canada, Guelph, ON), metaflumizone $240 \mathrm{~g} \mathrm{~L}^{-1}$ SC (Alverde ${ }^{\mathrm{TM}} 240 \mathrm{SC}$, BASF Canada, Mississauga, ON) and chlorantraniliprole $350 \mathrm{~g} \mathrm{~kg}^{-1}$ WG (Altacor ${ }^{\circledR} 35$ WG, DuPont Canada, Mississauga, ON)] and fungicides, myclobutanil $400 \mathrm{~g} \mathrm{~kg}^{-1}$ WG (Nova $^{\circledR} 40$ W, Dow Agrosciences Canada, Calgary, AB), potassium bicarbonate (Milstop ${ }^{\circledR}$, Bioworks USA, Victor, NY), and cyprodinil 375 + fludioxonil $250 \mathrm{~g} \mathrm{~kg}^{-1}$ WG (Switch ${ }^{\circledR}$, Syngenta Crop Protection Canada, Guelph, ON).] were tested. Abamectin was included as a positive control as it is known to be harmful to some BCAs, such as $O$. insidiosus. ${ }^{9}$ The recommended rate (RR) of each product and calculated concentration ( $\mathrm{mg} \mathrm{L}^{-1}$ ) of pesticide in spray solution at RR were: imidacloprid $267 \mathrm{~g} \mathrm{ha}^{-1}, 160 \mathrm{mg} \mathrm{L}^{-1}$; abamectin $5.7 \mathrm{~g} \mathrm{ha}^{-1}, 0.108 \mathrm{mg} \mathrm{L}^{-1}$; metaflumizone $288 \mathrm{~g} \mathrm{ha}^{-1}, 69 \mathrm{mg} \mathrm{L}^{-1}$; chlorantraniliprole $25 \mathrm{~g} \mathrm{ha}^{-1} ; 9 \mathrm{mg} \mathrm{L}^{-1}$; myclobutanil $340 \mathrm{~g} \mathrm{ha}^{-1}$, $136 \mathrm{mg} \mathrm{L}^{-1}$; potassium bicarbonate $560 \mathrm{~g} \mathrm{ha}^{-1}, 476 \mathrm{mg} \mathrm{L}^{-1}$; and cyprodinil + fludioxonil $833 \mathrm{~g} \mathrm{ha}^{-1}, 521 \mathrm{mg} \mathrm{L}^{-1}$. Pesticides were dispersed in water to create stock solutions of $1000 \mathrm{mg} \mathrm{L}^{-1}$; dilutions were subsequently prepared to obtain the desired concentrations. If a range of rates was presented on the Canadian product label, the middle rate was considered the RR.

\subsection{Laboratory bioassays}

Residual contact toxicity of the pesticides to the BCAs was determined using a leaf dip bioassay. Petioles of excised green bean leaves were inserted into flower picks filled with distilled water. Each leaf was dipped for ca. $5 \mathrm{~s}$ into a pesticide treatment and dried in a fume-hood for ca. $1.5 \mathrm{~h}$ by inserting the end of the picks into a wire rack. Each pesticide was tested at two concentrations: RR for greenhouse use and twice RR. Treated, dried leaves were transferred to post-treatment containers and ca. 15 adult BCAs were placed on the leaf. Post-treatment containers consisted of ventilated $10 \mathrm{~cm}$ Petri dishes, $5 \mathrm{~cm}$ Petri dishes, and plastic vials ( $2 \mathrm{~cm}$ diameter $\times 7 \mathrm{~cm}$ height) for 0 . insidiosus, $A$. swirskii and E. eremicus, respectively. Orius insidiosus and $E$. eremicus were provided with E. kuehniella eggs and honey for food, respectively. Each treatment was replicated four times and mortality was assessed at $48 \mathrm{~h}$. Post-treatment containers were maintained at $25 \pm 1{ }^{\circ} \mathrm{C}, 70-80 \% \mathrm{RH}$, and $16: 8 \mathrm{~h}$ light: dark photoperiod for O. insidiosus, and 12:12 h light: dark photoperiod for A. swirskii and E. eremicus.

Pesticides were ranked as harmless ( $<25 \%$ mortality), slightly harmful (25-50\%), moderately harmful (51-75\%) or harmful (>75\%) according to standards of the International Organization of Biological Control (IOBC) for semi-field or field trials. ${ }^{10}$ Control mortality did not exceed $20 \%, 10 \%$ and $25 \%$ for bioassays with $O$. insidiosus, A. swirskii and E. eremicus, respectively. Adults that went missing were not included in the analysis. Abbott's formula was used to correct for natural mortality. ${ }^{11}$ Data were subjected to an analysis of variance using PROC GLM in SAS v. 9.1 and differences among means were determined with Tukey's least significant means test. ${ }^{12}$ Tests were performed at a significance level of $\alpha=0.05$.

\subsection{Greenhouse bioassays}

Orius insidiosus was purchased from KBSC and A. swirskii and E. eremicus were purchased from BBSC for use in the greenhouse bioassays. Orius insidiosus and A. swirskii adults were used in the bioassay immediately upon arrival; $E$. eremicus were purchased in advance and emerged as described for laboratory bioassays.

Formulated pesticides evaluated in the greenhouse bioassay included abamectin, metaflumizone, potassium bicarbonate and cyprodinil + fludioxonil. Because abamectin and metaflumizone were slightly to moderately harmful to one or more BCA in our laboratory bioassays, further evaluation of these products in the greenhouse was warranted. Potassium bicarbonate and cyprodinil + fludioxonil were included because they were new fungicides with few available toxicity data. There also had been anecdotal evidence from local greenhouse vegetable growers that potassium bicarbonate negatively impacted BCA populations. Control leaves were treated with tap water only.

Tests were conducted at the Greenhouse and Processing Crops Research Centre, Agriculture and Agri Food Canada, Harrow ON. Greenhouse cucumber plants (Cucumis sativus L. var. sativus; v. Camaro) were grown using commercial production practices in 6 rows of 12 plants. Once the plants reached ca. ninth leaf stage, pesticides were applied using a carbon dioxide pressured backpack sprayer (R\&D Sprayers, Opelousas, LA) at RR until runoff to the adaxial and abaxial surfaces of each leaf in a randomized 
complete block design. Two plants per row were sprayed with each treatment.

Plastic clip cages, the inner surfaces of which were sprayed at the same time as the plants, were used to confine BCA adults to the abaxial leaf surface of treated plants. Clip cages for $O$. insidiosus consisted of a $10 \mathrm{~cm}$ plastic Petri dish bottom with a $6 \mathrm{~cm}$ hole in the top covered with thrip-proof screening for ventilation. Cages were attached to leaves using two binder clips and a piece of cardboard for backing. Clip cages for A. swirskii and E. eremicus consisted of a $3.5 \times 1 \mathrm{~cm}$ Petri dish with a $3 \mathrm{~cm}$ diameter hole in the top covered with thrip-proof screening. Cage backings consisted of a round piece of shoe insole glued to a $5 \mathrm{~cm}$ diameter plastic disc. Three clip cages were affixed to the leaves on one plant per treatment per row 1 and 8 days after treatment (DAT). Ten to 15 adults of each BCA were then placed in separate treated cages in each row. Mortality was assessed at $24 \mathrm{~h}$ at each residual time and BCAs were considered dead if they did not move when probed.

Pesticides were ranked as described in Section 2.3. Control mortality did not exceed 15\%, 10\% and 30\% for bioassays with $O$. insidiosus, A. swirskii and E. eremicus, respectively. Abbott's formula was used to correct for natural mortality. ${ }^{11}$ Adults that went missing were not included in the analysis. The $24 \mathrm{~h}$ residue mortality data for $O$. insidiosus failed to meet the assumptions of a parametric test and, therefore, a non-parametric Kruskal-Wallis test was performed using PROC NPAR1WAY to determine differences between means. Data for $A$. swirskii were almost entirely null and therefore did not conform to the assumptions of statistical testing. Data for E. eremicus were analyzed the same as the laboratory bioassay data.

\section{RESULTS}

\subsection{Laboratory Bioassays}

\subsubsection{Orius insidiosus}

There were no significant differences in mortality of $O$. insidiosus between treatments $(F=1.8 ; \mathrm{df}=3 ; 11 ; P=0.085$; Table 1$)$. Abamectin at RR and twice RR was slightly harmful and moderately harmful, respectively (Table 1). All other treatments were harmless (Table 1).

\subsubsection{Amblyseius swirskii}

Abamectin caused significantly higher mortality of $A$. swirskii $(\mathrm{F}=$ 2.87, $\mathrm{df}=3,11 ; P=0.0063$ ) at twice RR than all other treatments but was classified as harmless. All other treatments were harmless (Table 1).

\subsubsection{Eretmocerus eremicus}

Metaflumizone at twice RR caused significantly higher mortality of . eremicus $(\mathrm{F}=2.49 ; \mathrm{df}=3,11 ; P=0.0157)$ than abamectin at $\operatorname{RR}(P=0.01)$, potassium bicarbonate at $\operatorname{RR}(P=0.0212)$, potassium bicarbonate at twice $\mathrm{RR}(P=0.028)$, and cyprodinil + fludioxonil twice RR ( $P=0.0313$ ) (Table 1). Metaflumizone was slightly harmful at RR and moderately harmful at twice RR. There were no other significant differences among treatments and all other treatments were harmless (Table 1).

\subsection{Greenhouse Bioassays}

\subsubsection{Orius insidiosus}

Abamectin caused significantly higher $\left(\chi^{2}=25.47 ; \mathrm{df}=4\right.$; $P<0.0001)$ mortality than metaflumizone $\left(\chi^{2}=9.47 ; \mathrm{df}=1\right.$; $P=0.004)$, potassium bicarbonate $\left(\chi^{2}=9.47 ; \mathrm{df}=1 ; P=0.002\right)$, and cyprodinil + fludioxonil $\left(\chi^{2}=8.47 ; \mathrm{df}=1 ; P=0.004\right) 1 \mathrm{DAT}$, but was classified as harmless (Table 2). Abamectin did not cause significantly higher mortality than any of the other treatments 8 DAT. All other treatments were harmless 1 and 8 DAT (Table 2).

\subsubsection{Amblyseius swirskii}

All insecticide and fungicide residues were harmless to $A$. swirskii 1 and 8 DAT (Table 2).

\subsubsection{Eretmocerus eremicus}

Metaflumizone caused significantly higher mortality than abamectin $(P=0.0299)$ and cyprodinil + fludioxonil $(P=0.0217)$ 1 DAT (F = 3.0; df =8, 16; $P=0.0292$ ) (Table 2). Similarly, $8 \mathrm{~d}$ metaflumizone residues $(F=2.5 ; \mathrm{df}=8,16 ; P=0.0567)$ caused significantly higher mortality than abamectin $(P=0.0351)$ and cyprodinil + fludioxonil $(P=0.0304)$ (Table 2$)$. In both cases,

Table 1. Average corrected percentage mortality of Orius insidiosus, Amblyseius swirskii and Eretmocerus eremicus adults $48 \mathrm{~h}$ after exposure to leaf residues of formulated insecticides and fungicides at recommended rate (RR) and twice recommended rate $(2 \times \mathrm{RR})$ for greenhouse use. Means within columns followed by the same letter are not significantly different (Tukey's, $\alpha=0.05$ )

\begin{tabular}{|c|c|c|c|c|c|}
\hline \multirow[b]{2}{*}{ Treatment } & \multirow[b]{2}{*}{ Rate $\left(\mathrm{mg} \mathrm{L}^{-1}\right)$} & \multicolumn{3}{|c|}{ Average Corrected Mortality (\%) ( \pm SE) } & \\
\hline & & Orius insidiosus & Amblyseius swirskii & Eretmocerus eremicus & \\
\hline \multicolumn{6}{|l|}{ Insecticides } \\
\hline abamectin & $\mathrm{RR}$ & 0.1 & $40.6( \pm 22.32) a$ & $2.5( \pm 2.5) \mathrm{b}$ & ob \\
\hline$\left(\right.$ Avid $\left.^{\circledR} 1.9 \% \mathrm{EC}\right)$ & $2 \times R R$ & 0.2 & $58.7( \pm 16.95) a$ & $22.8( \pm 10.2) \mathrm{a}$ & $13.8( \pm 7.9) a b$ \\
\hline metaflumizone & $\mathrm{RR}$ & 69 & $14.5( \pm 11.64) a$ & $\mathrm{Ob}$ & $35.8( \pm 11.2) a b$ \\
\hline$\left(\right.$ Alverde $\left.^{\mathrm{TM}} 240 \mathrm{SC}\right)$ & $2 \times R R$ & 138 & $8.8( \pm 4.92) \mathrm{a}$ & $\mathrm{Ob}$ & $46.8( \pm 11.8) \mathrm{a}$ \\
\hline chlorantraniliprole & $\mathrm{RR}$ & 8 & $15.8( \pm 7.40) \mathrm{a}$ & $\mathrm{Ob}$ & $8.8( \pm 8.8) a b$ \\
\hline$\left(\right.$ Altacor $^{\circledR} 35$ WG) & $2 \times R R$ & 16 & $14.3( \pm 2.25) \mathrm{a}$ & $\mathrm{Ob}$ & $19.5( \pm 11.8) a b$ \\
\hline \multicolumn{6}{|l|}{ Fungicides } \\
\hline myclobutanil & $\mathrm{RR}$ & 136 & $7.5( \pm 3.06) a$ & $5.0( \pm 2.9) b$ & $14.5( \pm 4.1) \mathrm{ab}$ \\
\hline$\left(\mathrm{Nova}^{\circledR} 40 \mathrm{~W}\right)$ & $2 \times \mathrm{RR}$ & 272 & $17.0( \pm 10.97) \mathrm{a}$ & $5.3( \pm 3.0) b$ & $19.5( \pm 8.2) \mathrm{ab}$ \\
\hline potassium bicarbonate & $\mathrm{RR}$ & 476 & $19.8( \pm 9.29) \mathrm{a}$ & $2.5( \pm 2.5) \mathrm{b}$ & $3.3( \pm 3.3) b$ \\
\hline (Milstop ${ }^{\circledR}$ ) & $2 \times \mathrm{RR}$ & 952 & $8.8( \pm 5.15) a$ & $2.5( \pm 2.5) b$ & $4.5( \pm 1.6) b$ \\
\hline cyprodinil + fludioxonil & $\mathrm{RR}$ & 520 & $9.5( \pm 4.35) \mathrm{a}$ & $0 b$ & $13.3( \pm 8.4) \mathrm{ab}$ \\
\hline$\left(\right.$ Switch ${ }^{\circledR} 62.5$ WG) & $2 \times R R$ & 1041 & $11.8( \pm 4.66) \mathrm{a}$ & $\mathrm{Ob}$ & $5.0( \pm 5.0) \mathrm{b}$ \\
\hline
\end{tabular}


Table 2. Average corrected percentage mortality of Orius insidiosus, Amblyseius swirskii and Eretmocerus eremicus adults $24 \mathrm{~h}$ after exposure to 1,8 and $15 \mathrm{~d}$ old residues of formulated insecticides and fungicides at recommended rate on greenhouse cucumber. Means within columns followed by the same letter are not significantly different (Tukey's; $\alpha=0.05$ )

Average Corrected Mortality (\%) ( \pm SE)

\begin{tabular}{|c|c|c|c|c|c|c|c|}
\hline \multirow[b]{3}{*}{ Treatment } & \multicolumn{7}{|c|}{ Average Corrected Mortality (\%) ( \pm SE) } \\
\hline & \multicolumn{2}{|c|}{ Orius insidiosus } & \multicolumn{2}{|c|}{ Amblyseius swirskii } & \multicolumn{3}{|c|}{ Eretmocerus eremicus } \\
\hline & $1 \mathrm{~d}$ Residues & $8 \mathrm{~d}$ Residues & $1 \mathrm{~d}$ Residues & $8 \mathrm{~d}$ Residues & $1 \mathrm{~d}$ Residues & $8 \mathrm{~d}$ Residues & $15 d_{\text {Residues }}^{a}$ \\
\hline $\begin{array}{l}\text { abamectin } \\
\left.\text { (Avid }^{\circledR} 1.9 \% \mathrm{EC}\right)\end{array}$ & $15.3( \pm 0.05) b$ & $7.2( \pm 0.03) \mathrm{a}$ & 0 & 0 & $4.4( \pm 0.04) b$ & $3.0( \pm 0.02) b$ & - \\
\hline $\begin{array}{l}\text { metaflumizone } \\
\text { (Alverde }^{\mathrm{TM}} 240 \mathrm{SC} \text { ) }\end{array}$ & 0a & $2.7( \pm 0.02) a$ & 0 & 0 & $36.8( \pm 0.13) a$ & $37.6( \pm 0.15) \mathrm{a}$ & $4.4( \pm 0.04)$ \\
\hline $\begin{array}{l}\text { potassium bicarbonate } \\
\text { (Milstop }^{\circledR} \text { ) }\end{array}$ & $0 a$ & $3.0( \pm 0.02) a$ & $5.0( \pm 0.05)$ & 0 & $16.2( \pm 0.07) a b$ & $5.2( \pm 0.04) \mathrm{ab}$ & - \\
\hline $\begin{array}{l}\text { cyprodinil + fludioxonil } \\
\text { (Switch }{ }^{\circledR} 62.5 \text { WG) }\end{array}$ & 0a & $2.9( \pm 0.03) \mathrm{a}$ & 0 & $1.0 \pm 0.02$ & $2.8( \pm 0.02) b$ & $2.2( \pm 0.01) b$ & - \\
\hline
\end{tabular}

metaflumizone was classified as slightly harmful. However, $15 \mathrm{~d}$ residues of metaflumizone were harmless. All other treatments were harmless to E. eremicus as 1 and 8 day-old residues (Table 2).

\section{DISCUSSION}

Abamectin was slightly to moderately harmful to $O$. insidiosus adults following leaf dip bioassays and harmless in the greenhouse bioassay. Similarly, previous studies have reported abamectin to be harmful to $O$. insidiosus during laboratory trials. For instance, Shipp et al. ${ }^{9}$ reported that abamectin caused between 96 and $100 \%$ mortality of $O$. insidiosus adults up to 6 DAT. However, other studies also have reported abamectin to be harmful under greenhouse and field conditions. Studebaker and Kring ${ }^{13}$ found that abamectin was harmful to adults up to 3 DAT on field cotton. Similarly, Studebaker and Kring ${ }^{14}$ reported abamectin to be harmful on greenhouse and field cotton, causing up to $100 \%$ mortality 1 DAT. Abamectin is subject to photolysis when exposed to sunlight. ${ }^{15,16}$ Our study was conducted in July in Southern Ontario during periods of intense sunlight and high ambient temperatures. After being applied under these conditions, abamectin may have rapidly degraded to harmless levels.

Metaflumizone and chlorantraniliprole were harmless to $O$. insidiosus in both laboratory and greenhouse trials, as were all fungicides tested. These products can therefore be safely applied in greenhouses prior to releasing $O$. insidiosus for WFT control.

Amblyseius swirskii is a relatively new BCA and few data exist on its susceptibility to pesticides. We found it to be highly tolerant to all insecticides and fungicides tested. Other predatory mites are more susceptible to similar pesticides. Bostanian and Akalach ${ }^{17}$ reported abamectin was toxic to Phytoseiulus persimilis Athias-Henriot and Amblyseius fallacis Garman adults following direct application, and Kim et al. ${ }^{18}$ found abamectin caused up to $92 \%$ mortality of Amblyseius cucumeris Oudemans adults 5 DAT. Fungicides also are toxic to some predatory mites. For instance, application of myclobutanil + tolyfluanid to apple orchards significantly reduced populations of Amblyseius andersoni Berlese. ${ }^{19}$ Similarly, Bower et $a .^{20}$ found that mancozeb and benomyl severely reduced orchard populations of A. fallacis. Amblyseius swirskii appears to be a viable, chemical-tolerant BCA option for GWF and WFT management in greenhouses.
Abamectin and chlorantraniliprole were harmless to E. eremicus; metaflumizone, however, was slightly harmful in laboratory trials and up to 8 DAT in the greenhouse bioassays. Other researchers have reported varying susceptibility of Eretmocerus species to different insecticides. González-Zamora et al..$^{21}$ found abamectin and seven other insecticides harmless when applied directly to Eretmocerus mundus Meriot pupae. Acrinathrin, imidacloprid, and methiocarb were moderately harmful. González-Zamora et al. ${ }^{22}$ also reported that indoxacarb was slightly harmful and that methomyl was harmful to $E$. mundus adults. All fungicides tested were harmless to $E$. eremicus. They also tested the effect of myclobutanil and five other fungicides on E. mundus pupae with similar results. ${ }^{21}$

Our study focused on the mortality of BCA adults following exposure to pesticide residues. However, further research is required to give a complete picture of the toxicity of these products to BCAs. Established BCA populations are at risk of contact with foliar spray during application. As pesticide toxicity can vary with exposure route, it would be valuable to determine the direct contact toxicity of these pesticides to BCAs. For instance, spinosad was found to be moderately harmful to $O$. insidiosus following direct contact, but was harmless as a residue. ${ }^{23}$ Furthermore, most toxicity studies on BCAs focus solely on mortality. However, sublethal doses of pesticides are known to affect the physiology and/or behaviour of non-target species. ${ }^{4}$ Sub-lethal effects can include changes in longevity, development, fecundity and predation capacity. ${ }^{4,24}$ For instance, Elzen ${ }^{25}$ reported that cyfluthrin, fipronil, and profenofos reduced the predation rate of $O$. insidiosus adults. Kim et al. ${ }^{18}$ found that abamectin, emamectin benzoate, fipronil, and pyraclofos significantly reduced egg production in female A. cucumeris. Sub-lethal effects such as these can reduce BCA population numbers and ultimately effectiveness in controlling pest populations. ${ }^{24}$ Therefore, it is important to study potential sub-lethal effects of these pesticides to accurately determine their overall impact on greenhouse biological control.

In conclusion, the novel, reduced risk insecticides metaflumizone and chlorantraniliprole appear relatively harmless as residues to adult $O$. insidiosus, $A$. swirskii and E. eremicus, and therefore these products could be safely applied prior to release and/or establishment of these BCAs. Metaflumizone was slightly toxic to E. eremicus and should be used with caution where these parasitoids are 
released for GWF management. Finally, all fungicides tested could be applied for PM prior to release of all three species of BCA. Further study is justified on the effects of these pesticides on BCAs to fully incorporate them into greenhouse IPM programs. However, with their novel modes of action and low residual toxicity to BCAs, these chemicals appear promising additions to greenhouse vegetable production in Canada.

\section{ACKNOWLEDGEMENTS}

We thank Biobest Biological Systems Canada and Koppert Biological Systems Canada for donating BCAs and Ida Podrug, Kelly O'Keefe, and Dr. Rose Buitenhuis for technical support. Funding for this project was provided by a Canada Ontario Research and Development (CORD) IV grant administered by the Agricultural Adaptation Council and provided to the Ontario Greenhouse Vegetable Growers and a grant from the Minor Use Research Initiative, Pest Management Centre, Agriculture and Agri-Food Canada.

\section{REFERENCES}

1 van Lenteren JC, Biological control in protected crops: where do we go? Pestic Sci 36:321-327 (1992).

2 Weintraub PG, Kleitman S, Mori R, Shapira N and Palevsky E, Control of the broadmite (Polyphagotarsonemus latus (Banks) on organic greenhouse sweet peppers (Capsicum annuum L.) with the predatory mite, Neoseiulus cucumeris (Oudemans). Biol Cont 27:300-309 (2003)

3 Ontario Ministry of Agriculture, Food and Rural Affairs, Growing Greenhouse Vegetables. Publication 371 (2005).

4 Croft BA, Arthropod Biological Control Agents and Pesticides. John Wiley \& Sons, New York (1990).

5 Hajek A, Natural Enemies: An Introduction to Biological Control. Cambridge University Press, Cambridge (2004).

6 Hassan SA, Bigler F, Bogenschutz H, Boller B, Brun J, Calis JNM, et al, Results of the sixth joint pesticide testing programme of the IOBC/WPRS-working group Pesticides and Beneficial Organisms. Entomophaga 39:107-119 (1994).

7 Yardim EN and Edwards CA, The influence of chemical management of pests, diseases and weeds on pest and predatory arthropods associated with tomatoes. Agr Ecosyst Environ 70:31-48 (1998).

8 Youn YN, Seo MJ, Shin JG, Jang C and Yu YM, Toxicity of greenhouse pesticides to multicoloured Asian lady beetles, Harmonia axyridis (Coleoptera: Coccinellidae). Biol Cont 28:164-170 (2003).

9 Shipp JL, Wang K and Ferguson G, Residual toxicity of avermectin b1 and pyridaben to eight commercially produced beneficial arthropod species used for control of greenhouse pests. Biol Cont 17:125-131 (2000)
10 Hassan SA, Standard methods to test the side-effects of pesticides on natural enemies of insects and mites developed by the IOBC/WPRS Working Group 'Pesticides and Beneficial Organisms'. Bulletin OEPP/EPPO Bulletin 15:214-255 (1985)

11 Abbott WS, A method of computing the effectiveness of an insecticide. J Econ Entomol 18:265-267 (1925).

12 SAS Institute, PROC users manual. SAS Institute, Cary, NC (2005).

13 Studebaker GE and Kring TJ, Effects of various insecticide residues in cotton on gender and developmental stage of the insidious flower bug (Hemiptera: Anthocoridae). J Entomol Sci 38:409-419 (2003).

14 Studebaker GE and Kring TJ, Effects of insecticides on Orius insidiosus (Hemiptera: Anthocoridae), measured by field, greenhouse and petri dish bioassays. Fla Entomol 86:178-185 (2003).

15 Bostanian NJ and Akalach M, The contact toxicity of indoxacarb and five other insecticides to Orius insidiosus (Hemiptera: Anthocoridae) and Aphidius colemani (Hymenoptera: Braconidae), beneficials used in the greenhouse industry. Pest Manag Sci 60:1231-1236 (2004).

16 Tomlin CDS, (ed.) The Pesticide Manual, British Crop Protection Council, Alton, Hants., UK (2000).

17 Bostanian NJ and Akalach M, The effect of indoxacarb and five other insecticides on Phytoseiulus persimilis (Acari: Phytodeiidae), Amblyseius fallacis (Acari: Phytoseiidae) and nymphs of Orius insidiosus (Hemiptera: Anthocoridae). Pest Manag Sci 62:334-339 (2006).

18 Kim SS, Seo SG, Park JD, Kim SG and Kim DI, Effects of selected pesticides on the predatory mite, Amblyseius cucumeris (Acari: Phytoseiidae). J Entomol Sci 40:107-114 (2005).

19 Raudonis L, Surviliene E and Valiuskaite A, Toxicity of pesticides to predatory mites and insects in apple-tree site under field conditions. Environ Toxicol 19:291-295 (2004).

20 Bower K, Berkett LP and Costante JF, Nontarget effect of a fungicide spray program on phytophagous and predacious mite populations in a scab-resistant orchard. Environ Entomol 24:423-430 (1995).

21 González-Zamora JE, Gallardo JM and Garcia MM, Toxicity of different pesticides on pupae of Eretmocerus mundus Mercet (Hymenoptera: Aphelinidae) parasitizing Bemisia tabaci (Genn.) (Homoptera: Aleyrodidae). IOBC/WPRS Bulletin 20:114-120 (1997).

22 González-Zamora JE, Leira D, Bellido MJ and Avilla C, Evaluation of the effect of different insecticides on the survival and capacity of Eretmocerus mundus Mercot to control Bemisia tabaci (Gennadius) populations. Crop Prot 23:611-618 (2004).

23 Jones T, Scott-Dupree C, Harris R, Shipp L and Harris B, The efficacy of spinosad against the western flower thrips, Frankliniella occidentalis, and its impact on associated biological control agents on greenhouse cucumbers in southern Ontario. Pest Manag Sci 61:179-185 (2005).

24 Elzen GW, Sublethal effects of pesticides on beneficial parasitoids, in: Pesticides and Non-Target Invertebrates, ed. by Jepson PC, Intercept, Wimborne, Dorset, pp. 129-150 (1989).

25 Elzen GW, Lethal and sublethal effects of insecticide residues on Orius insidiosus (Hemiptera: Anthocoridae) and Geocoris punctipes (Hemiptera: Lygaeidae). J Econ Entomol 91:55-59 (2001). 